\title{
Impaired Uptake of Glutathione by Hepatic Mitochondria from Chronic Ethanol-fed Rats \\ Tracer Kinetic Studies In Vitro and In Vivo and Susceptibility to Oxidant Stress
}

\author{
José C. Fernández-Checa, Carmen García-Ruiz, Murad Ookhtens, and Neil Kaplowitz
}

Division of Gastrointestinal and Liver Diseases, University of Southern California School of Medicine, and

the United States Department of Veterans Affairs, Outpatient Clinic, Los Angeles, California 90033

\begin{abstract}
Isolated hepatocytes incubated with $\left[{ }^{35} \mathrm{~S}\right]-$ methionine were examined for the time-dependent accumulation of $\left[{ }^{35} \mathrm{~S}\right]$-glutathione (GSH) in cytosol and mitochondria, the latter confirmed by density gradient purification. In GSH-depleted and -repleted hepatocytes, the increase of specific activity of mitochondrial GSH lagged behind cytosol, reaching nearly the same specific activity by 1-2 h. However, in hepatocytes from ethanol-fed rats, the rate of increase of total GSH specific radioactivity in mitochondria was markedly suppressed. In in vivo steady-state experiments, the mass transport of GSH from cytosol to mitochondria and vice versa was $18 \mathrm{nmol} / \mathrm{min}$ per g liver, indicating that the half-life of mitochondrial GSH was $\sim 18 \mathrm{~min}$ in controls. The fractional transport rate of GSH from cytosol to mitochondria, but not mitochondria to cytosol, was significantly reduced in the livers of ethanol-fed rats. Thus, ethanolfed rats exhibit a decreased mitochondrial GSH pool size due to an impaired entry of cytosol GSH into mitochondria. Hepatocytes from ethanol-fed rats exhibited a greater susceptibility to the oxidant stress-induced cell death from tert-butylhydroperoxide. Incubation with glutathione monoethyl ester normalized the mitochondrial GSH and protected against the increased susceptibility to $t$-butylhydroperoxide, which was directly related to the lowered mitochondrial GSH pool size in ethanolfed cells. (J. Clin. Invest. 1991 . 87:397-405.) Key words: compartmentalization • transport • oxidant stress • glutathione ester - cell death • tert-butylhydroperoxide
\end{abstract}

\section{Introduction}

Glutathione (GSH) ${ }^{1}$ plays a key role in detoxification of electrophiles and peroxides $(1,2)$ and has been proposed that GSH is a storage and transfer vehicle for cysteine (3). The liver plays an important role in GSH homeostasis because it supplies GSH

\section{Address correspondence to José C. Fernández-Checa, Division of Gas- trointestinal and Liver Diseases, USC School of Medicine, 2025 Zonal Ave., LAC 11221, Los Angeles, CA 90033. \\ Received for publication 21 February 1990 and in revised form 26 September 1990.}

1. Abbreviations used in this paper: GSH, reduced glutathione; GSSG, oxidized glutathione; GSH-EE, glutathione monoethyl ester; LDH, lactic dehydrogenase; $\mathrm{SDH}$, succinic dehydrogenase; $\mathrm{t}-\mathrm{BOOH}$, tert-butylhydroperoxide.

J. Clin. Invest.

(C) The American Society for Clinical Investigation, Inc. 0021-9738/91/02/0397/09 \$2.00

Volume 87, February 1991, 397-405 to plasma and bile to support the interorgan homeostasis $(4,5)$. GSH is biosynthesized exclusively in cytosol where the bulk of it is found. However, 10-15\% of the hepatic GSH is sequestered in organelles, presumed to be almost exclusively mitochondria (6). The origin of this mitochondrial pool has recently been clarified using tracer kinetic studies which reveal that mitochondrial GSH is derived from cytosol (7).

We have been studying the effects of chronic ethanol intake on the homeostasis of hepatic GSH and have identified an impairment in mitochondrial GSH sequestration $(8,9)$. The rationale for these studies: (a) A variety of mechanisms and evidence for the existence of oxidant stress have been found in ethanol-fed animals leading to the hypothesis that oxidant stress, including lipid peroxidation, may contribute to the pathogenesis of alcoholic liver disease (10). (b) The mitochondria of alcohol-fed animals show structural and functional changes suggesting that this organelle is an important target of ethanol toxicity $(11,12)$. (c) The small pool of GSH in mitochondria maintains the integrity of this organelle against oxidant stress produced both under basal aerobic conditions and under conditions of stimulation from exogenous factors; indeed, the depletion of this pool leads to loss of cell viability (13, 14). Our initial studies demonstrated a selective decreased mitochondrial GSH pool size in rat liver with chronic ethanol feeding and a decrease in the accumulation of GSH in mitochondria when the cytosol GSH was increased (9). Our previous studies, however, did not address four critical issues which are the subject of this report. First, it is important to prove that the compartmentalized GSH in hepatocytes indeed is mainly mitochondrial. Second, it is important to determine if the decrease in accumulation of mitochondrial GSH in hepatocytes from ethanol-fed rats is due to impaired uptake of GSH from cytosol or enhanced efflux and loss of GSH from mitochondria. Third, the possibility that impaired accumulation of GSH in mitochondria in the isolated hepatocytes from ethanol-fed rats is an in vitro artifact needs to be excluded by determining if the same phenomenon occurs in vivo; concurrently, information on the normal steady-state kinetics of uptake and release of GSH from mitochondria in vivo is lacking, which is an additional important goal of the present studies; fourth, because elevation of cytosol GSH levels does not raise mitochondrial GSH in hepatocytes from ethanol-fed rats and because GSH ester has been shown to raise GSH in mitochondria of skeletal muscle and heart (15), the possibility that the ester might restore mitochondrial GSH in hepatocytes from ethanol-fed rats needs to be examined. In addition, the potential pathophysiologic consequence of the decreased mitochondrial GSH pool in chronic ethanol-fed rats has been examined by determining the susceptibility of isolated cells to the exogenous oxidant stress induced by tert-butylhydroperoxide ( $t$ $\mathrm{BOOH}$ ) and the effect of restoration of normal mitochondrial GSH levels with the use of GSH ester on this susceptibility. 


\section{Methods}

Materials and animals. Feeding the liquid diet (16) (Bioserv, Rahway, $\mathrm{NJ})$ to male Sprague-Dawley rats and several reagents used were as described previously $(8,9)$. All studies were performed on overnightfasted animals after 6 wk of feeding unless stated otherwise.

Cell isolation. Hepatocytes from pair- and ethanol-fed rats were isolated according to Moldeus (17) and handled as previously reported $(18,19)$. Initial viability $(\geq 90 \%)$ did not change significantly over the course of the incubations in the modified Fisher's medium, as described in our previous work (8).

Incubation of cells with $L-\left[{ }^{35} S\right]$ methionine to label GSH. To insure a maximal labeling of GSH from the precursor, $\left.\mathrm{L}-{ }^{35} \mathrm{~S}\right]$ methionine, hepatocytes were first depleted of GSH by preincubation with DEM (0.8 $\mathrm{mM}$, for $15 \mathrm{~min}$ ) in Krebs-Henseleit buffer. Cells were then washed twice with Krebs buffer and finally resuspended in modified Fisher's medium. The same labeling experiments were performed in cells with replete GSH status. Hepatocytes were suspended at a concentration of $2-3 \times 10^{6}$ cells $/ \mathrm{ml}$ in the Fisher's medium supplemented with $1 \mathrm{mM}$ methionine and serine to replenish the GSH pool (20) plus 3-4 $\mu \mathrm{Ci} / \mathrm{ml}$ of $\mathrm{L}-\left[{ }^{35} \mathrm{~S}\right]$ methionine (Amersham, Boston, MA, sp act $1,164 \mathrm{Ci} / \mathrm{mmol}$ ). Cells were incubated as described previously $(8,9)$. At indicated time points (see figures) aliquots of cell suspensions were removed and cells were fractionated with digitonin into cytosol and particulate fractions as described previously $(8,9)$. Both fractions were derivatized to quantitate GSH mass and radioactivity by the HPLC method (21).

In some experiments, the particulate fraction was further fractionated in a continuous linear gradient of $40 \%$ metrizamide- $0.25 \mathrm{M}$ sucrose and centrifuged at $113,000 \mathrm{~g}$ for $1 \mathrm{~h}$ at $0^{\circ} \mathrm{C}$ in a SW40 Ti swing rotor (22). 1-ml fractions were collected automatically by an Auto Densi Flow II (Haake Buchler Instruments, Inc., Saddle Brook, NJ) and marker enzyme activities determined for lysosomes, microsomes, mitochondria, and GSH in each fraction.

In vivo experiments. Both pair- and ethanol-fed rats were anesthetized and tracheotomized. A tracer dose of $\mathrm{L}-\left[{ }^{35} \mathrm{~S}\right]$ methionine $(\sim 200$ $\mu \mathrm{Ci})$ was given i.v. (jugular vein), afterwhich biopsies ( $\sim 300-500 \mathrm{mg}$ tissue) from each liver were taken in a time course. The tissue was weighed, homogenized, and fractionated in a discontinuous Percoll gradient and centrifuged at $43,000 \mathrm{~g}$ for $1 \mathrm{~min}$ in a model SS-34 rotor (Sorvall Instruments, Newton, CT) (23). The density of the cytosol and mitochondrial fractions was $1.04-1.05 \mathrm{~g} / \mathrm{ml}$ and $1.085-1.095 \mathrm{~g} / \mathrm{ml}$, respectively, determined by density marker-beads (Sigma Chemical Co., St. Louis, MO). The cytosol- and mitochondrial-enriched fractions were collected and checked for cross-contamination by measuring the activity of lactic dehydrogenase (LDH) and succinic dehydrogenase (SDH), and both fractions were derivatized for analysis with a radio-HPLC technique to determine GSH mass and radioactivity as described below.

Synthesis of the glutathione monoester (GSH-EE). The GSH-EE was prepared by selective esterification of the glycine carboxyl group of glutathione with ethanol according to (24) using sulfuric acid in the esterification reaction, which was monitored by TLC (24). The product contained $98-100 \%$ GSH-EE.

Incubation of hepatocytes with GSH-EE and tert-butylhydroperoxide $(t-B O O H)$. Cells $\left(2 \times 10^{6}\right.$ cells $\left./ \mathrm{ml}\right)$ were first preincubated for 10 min with a moderate dose of DEM $(0.20 \mathrm{mM})$ to selectively deplete the cytosolic pool of GSH. Separate cells from the same preparations were incubated with $7 \mathrm{mM}$ GSH-EE for $2 \mathrm{~h}$ in a sulfur-free amino acid Fisher's medium to increase the levels of hepatic GSH as has been described for other cell types $(15,25-27)$. Cells were washed three times with fresh buffer to remove excess GSH-EE and were then treated with DEM $(0.32 \mathrm{mM})$ to deplete the cytosolic GSH pool size. At the end of both DEM treatment periods, cells were fractionated into soluble and particulate fractions as described $(8,9)$. GSH was determined in both fractions by the recycling method (28).

The DEM-treated cells $\left(2 \times 10^{6}\right.$ cells $\left./ \mathrm{ml}\right)$ were incubated in the presence of $\mathrm{t}-\mathrm{BOOH}(0-5 \mathrm{mM})$ in sulfur-free amino acid culture medium. After $45 \mathrm{~min}$ of incubation, a 1-ml aliquot was taken and cells were separated from medium by rapid spinning in a microfuge (Beckman Instruments Inc., Fullerton, CA). The cell death was expressed as the GSH S-transferase (GST) activity found in the medium as percentage of the total activity present in the cells, after lysing the cells with $10 \%$ Triton X-100, giving nearly identical results if trypan blue or LDH release were determined.

HPLC analyses. HPLC separations were made by the method of Reed et al. (21) using an Altex 110A double-pump gradient system with model 420 controller/programmer and an ISCO V4 detector. The outflow from the UV detector was passed through a Radiomatic FLOONE/Beta model CR radioactivity detector equipped with a $2.5-\mathrm{ml}$ liquid cell and an IBM PC XT data acquisition and processing system for both UV and radioactivity data. The HPLC outflow $(1 \mathrm{ml} / \mathrm{min})$ was mixed with Scintiverse E (Fisher Scientific Co., Pittsburgh, PA) scintillation cocktail $(4 \mathrm{ml} / \mathrm{min})$ to detect the radioactivity in a flow-through mode. Thus, both total and specific activity data for GSH were measured in the same separation from the computer-integrated values under the radioactivity and mass peaks. To express the radioactivity in percent dose units, we made the necessary quench corrections.

Assays. In some cases, cytosolic and mitochondrial total GSH content was determined after extraction with $10 \%$ TCA according to reference 28. LDH (cytosol marker) was measured by a kit (340-LD) from Sigma Chemical Co.; SDH (mitochondrial marker) was measured according to reference 29. Glucose-6-phosphatase (microsomal marker) and acid phosphatase (lysosomal marker), were measured by the release of inorganic phosphate (30) from glucose-6-phosphate and $\beta$-glycerophosphate, respectively. Protein concentration was determined by using the commercial reagent from Bio-Rad Laboratories (Richmond, CA).

Kinetic analysis and modeling. The tracer kinetic data for GSH from both pair-fed and ethanol-fed groups were fitted with a two-compartment model, representing the cytosolic and mitochondrial pools of GSH, to compute the rates of cytosolic and mitochondrial GSH transport (exchange) in vivo. Initially, the cytosolic data were fitted (nonlinear regression) separately with polynomial functions. Using a special feature of the SAAM program, these polynomial functions were then submitted as forcing functions in the SAAM program to represent the profiles of cytosolic radioactivity. This treatment allows the mitochondrial GSH compartment to "see" the response of the cytosol and adjust the transport parameters to fit the mitochondrial response. The mitochondrial data were then fitted by allowing the fractional rate of cytosolic to mitochondrial transport to adjust in the two-compartment model to obtain the best (least squares) fits to the data. The mean values of the data used for fitting were statistically weighted with their respective standard deviations. To maintain the pool sizes at steady state, the mitochondrial to cytosolic fractional transport rates were constrained in the SAAM runs according to the ratio of the mean of the two pool sizes measured for each group. Statistical comparisons between groups were by the unpaired $t$ test, and different treatments of the same cell preparations were compared by the paired $t$ test.

\section{Results}

Fractionation of the particulate fraction from digitonin-treated hepatocytes. In our previous work in which we have related changes in the compartmentation of hepatic GSH to ethanol intake $(8,9)$ we have used the technique of selective permeabilization of the plasma membrane with digitonin to obtain a particulate fraction-enriched in the mitochondrial marker, SDH $(8,31)$. However, to our knowledge no work has been done to demonstrate that the compartmentalized GSH identified by the digitonin permeabilization technique is indeed mitochondrial and not to some extent microsomal or lysosomal. Isolated hepatocytes from ad lib chow-fed rats were incubated in Fisher's medium in the presence of $1 \mathrm{mM}$ cold methionine as precursor and $\left[{ }^{35} \mathrm{~S}\right]$-methionine $(3-4 \mu \mathrm{Ci} / \mathrm{ml})$ for $2 \mathrm{~h}$ to label 
cellular GSH. Cells were fractionated into a cytosol and particulate fraction by exposing $4.5 \times 10^{6}$ cells $/ \mathrm{ml}$ to $80 \mu \mathrm{M}$ digitonin for $30 \mathrm{~s}$. The particulate fraction was homogenized in $0.25 \mathrm{M}$ sucrose and further fractionated in a metrizamide-sucrose continuous density gradient to resolve mitochondria from other subcellular organelles. Fig. 1 shows the profile of protein, different enzymatic activities, and GSH mass and radioactivity along the gradient. The enzymatic activities are expressed as the percentage of the activity from the particulate fraction obtained after digitonin, before density gradient fractionation. With this approach, we have obtained a separation of the respective lysosomal and microsomal markers, acid phosphatase and glucose-6-phosphatase, from the mitochondrial marker, SDH (Fig. 1). The LDH activity found in the top of the gradient was $<0.5 \%$ of the total LDH activity found in intact cells. As shown in Fig. 1 bottom, the gradient profile of labeled GSH and its mass coincide exactly with the mitochondrial SDH marker, suggesting that the GSH associated with the particulate fraction obtained from isolated hepatocytes is a mitochondrial pool.

In vitro labeling of GSH in cytosol and mitochondria of hepatocytes from pair- and ethanol-fed rats. Hepatocytes from pair- and ethanol-fed rats were first treated with DEM (0.8 $\mathrm{mM}, 15 \mathrm{~min}$ ) and then resuspended in modified Fisher's medium supplemented with $1 \mathrm{mM}$ methionine and $\left[{ }^{35} \mathrm{~S}\right] \mathrm{methio}-$ nine plus serine to label newly synthesized GSH from the precursor $\left[{ }^{35} \mathrm{~S}\right]$-methionine. At different time points, cells were fractionated into cytosol and particulate fractions, and both were analyzed for GSH mass and radioactivity. The mass of GSH, as determined from the UV channel of the HPLC profile, in cytosol of hepatocytes from ethanol-fed rats was replenished after depletion with DEM as effectively as the pair-fed cells in the course of $4 \mathrm{~h}$, whereas the mitochondrial GSH pool from the ethanol-treated group increased very little over time as compared to the pair-fed (Fig. 2).

The specific activity profiles of GSH synthesized in cytosol during the course of rapid repletion after DEM depletion and transfer of the labeled GSH from cytosol into the mitochondria are shown in Fig. 3. In both pair-fed controls (Fig. $2 A$ ) and ethanol-fed cases (Fig. $2 B$ ) the specific activity of cytosol GSH reached an essentially identical plateau value by $60 \mathrm{~min}$. The continued increase in pool size (Fig. 2) for the second 60-min interval is at near constant specific activity. Although strictly not a steady-state experiment (expanding pool sizes) the data permit an assessment of the changes of mitochondrial specific activity in relationship to cytosol and therefore provide an estimate of the rate of entry of newly synthesized cytosol GSH into mitochondria. In the pair-fed control case, the mitochondrial specific activity lags behind the cytosol and increases in a nearlinear manner to reach the cytosol plateau by $120 \mathrm{~min}$. In sharp contrast, in the cells from ethanol-fed rats, only a small increase in mitochondrial specific activity was observed.

To insure that the DEM pretreatment had not selectively induced mitochondrial damage due to a toxic effect in the ethanol-fed case, we also examined the incorporation of methionine into GSH in hepatocytes from pair-fed and ethanol-fed rats without DEM treatment. As shown in Fig. 4, similar increases in mass of GSH in cytosol were observed in both groups but the mitochondria showed a marked difference; the GSH pool increased in mitochondria of pair-fed cells in parallel with cytosol but did not increase at all in the cells from the ethanolfed rats. The results with incorporation of $\left[{ }^{35} \mathrm{~S}\right]$-methionine into GSH showed a similar pattern as in the DEM case (Fig. 5).
In the pair-fed cells, the specific activity in mitochondria lagged behind cytosol, reaching equilibrium at $2 \mathrm{~h}$. Again in the cells from ethanol-fed rats, the specific activity of mitochondrial GSH increased at a markedly diminished rate and did not reach isotopic equilibrium with cytosol during the course of the 4-h incubations. Thus, in both GSH-depleted and -repleted cases, under the incubation conditions in culture media, the hepatocyte mitochondria of ethanol-fed rats exhibit a similar

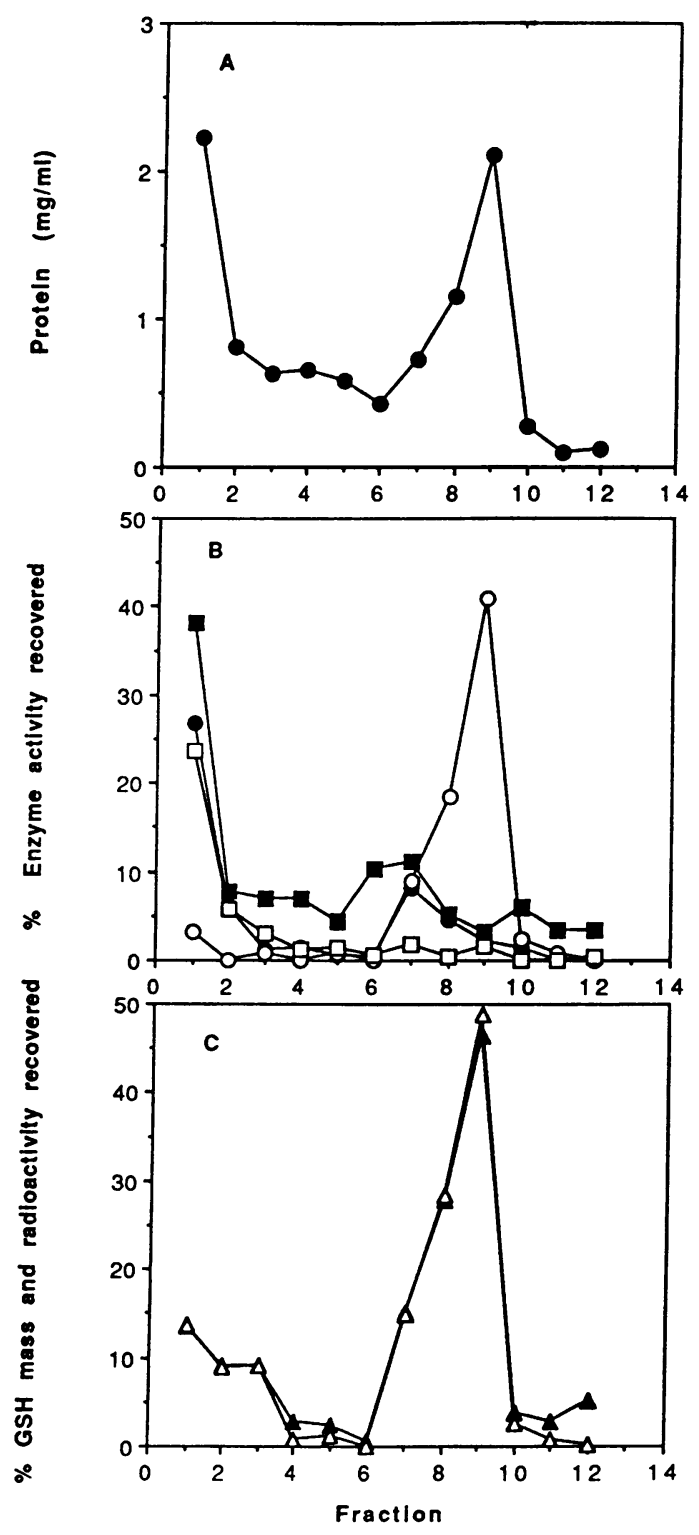

Figure 1. Fractionation of the particulate-fraction from digitoninpermeabilized hepatocytes. Freshly isolated hepatocytes were fractionated with digitonin $(80 \mu \mathrm{M}$ for $30 \mathrm{~s})$ as previously described $(8,9)$. The resulting particulate pellet was homogenized in $2.0 \mathrm{ml}$ of $0.25 \mathrm{M}$ sucrose, with a glass Dounce tight-fitting homogenizer (eight strokes) and then further fractionated in a continuous linear metrizamide-sucrose density gradient as described in Methods. Aliquots were taken from 12 fractions of the gradient to determine $(A)$ the protein content; $(B)$ the enzymatic activities for lysosomes (acid phosphatase) (๑), microsomes (glucose-6-phosphatase) (๑), cytosol (LDH) ( $\square$ ), and mitochondria (SDH) $(0) ;(C)$ the profile of GSH mass $(\Delta)$ and labeled GSH $(\Delta)$ along the gradient. The figure is from a single experiment and is representative of three experiments. 

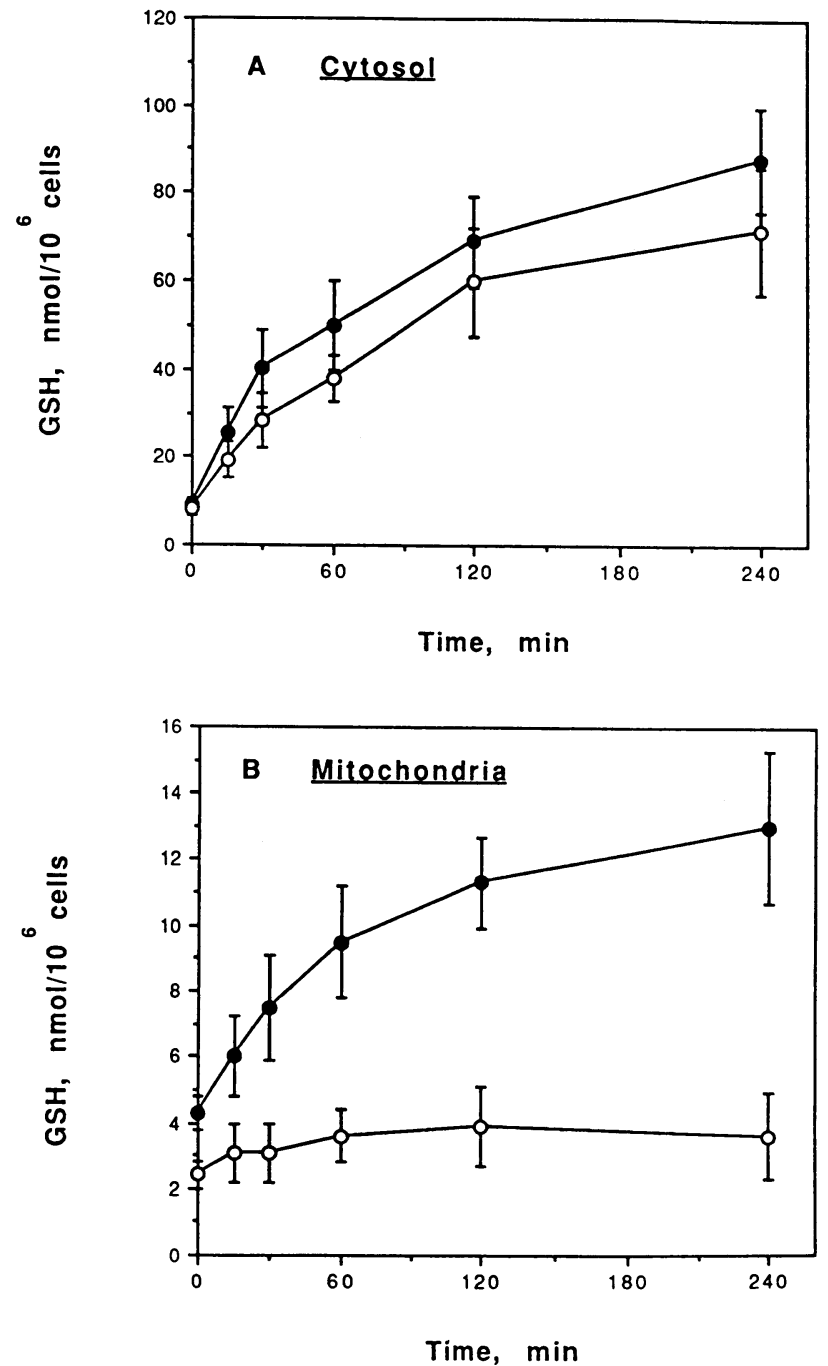

Figure 2. Accumulation of GSH in cytosol and mitochondrial fractions after depletion with DEM. Hepatocytes were first treated with DEM $(0.8 \mathrm{mM})$ to deplete GSH and then allowed to resynthesize GSH in the presence of methionine in modified Fisher's medium as described in Methods. At each time point, a 1-ml aliquot of cells (2-3 $\left.\times 10^{6}\right)$ was fractionated with digitonin into cytosol $(A)$ and mitochondrial $(B)$ fractions from (- $\bullet-)$ pair-fed and (- $\left.{ }_{-}\right)$ethanolfed hepatocytes. The GSH content was determined by the HPLC

(21). Data are mean \pm SD of $n=7$ cell preparations from each group.

marked suppression in the entry of radiolabeled GSH from cytosol.

In vivo GSH labeling. We have used a rapid subcellular fractionation technique to isolate mitochondrial- and cytosolenriched fractions to avoid artifactual redistributions of metabolites during the procedure. Within $\sim 10 \mathrm{~min}$ after the homogenization of the liver tissue, we obtained mitochondrial and cytosolic fractions enriched three and four times in LDH and SDH, respectively, with a recovery of $>90 \%$ for $\mathrm{LDH}$ in the cytosol fraction and of $55-60 \%$ for total SDH activity in the mitochondrial fraction with minimal cross-contamination (Table I). There was no difference in the enrichment of the fractions from pair- and ethanol-fed liver.

The levels (mass) of GSH in cytosolic and mitochondrial fractions from pair- and ethanol-fed livers were determined
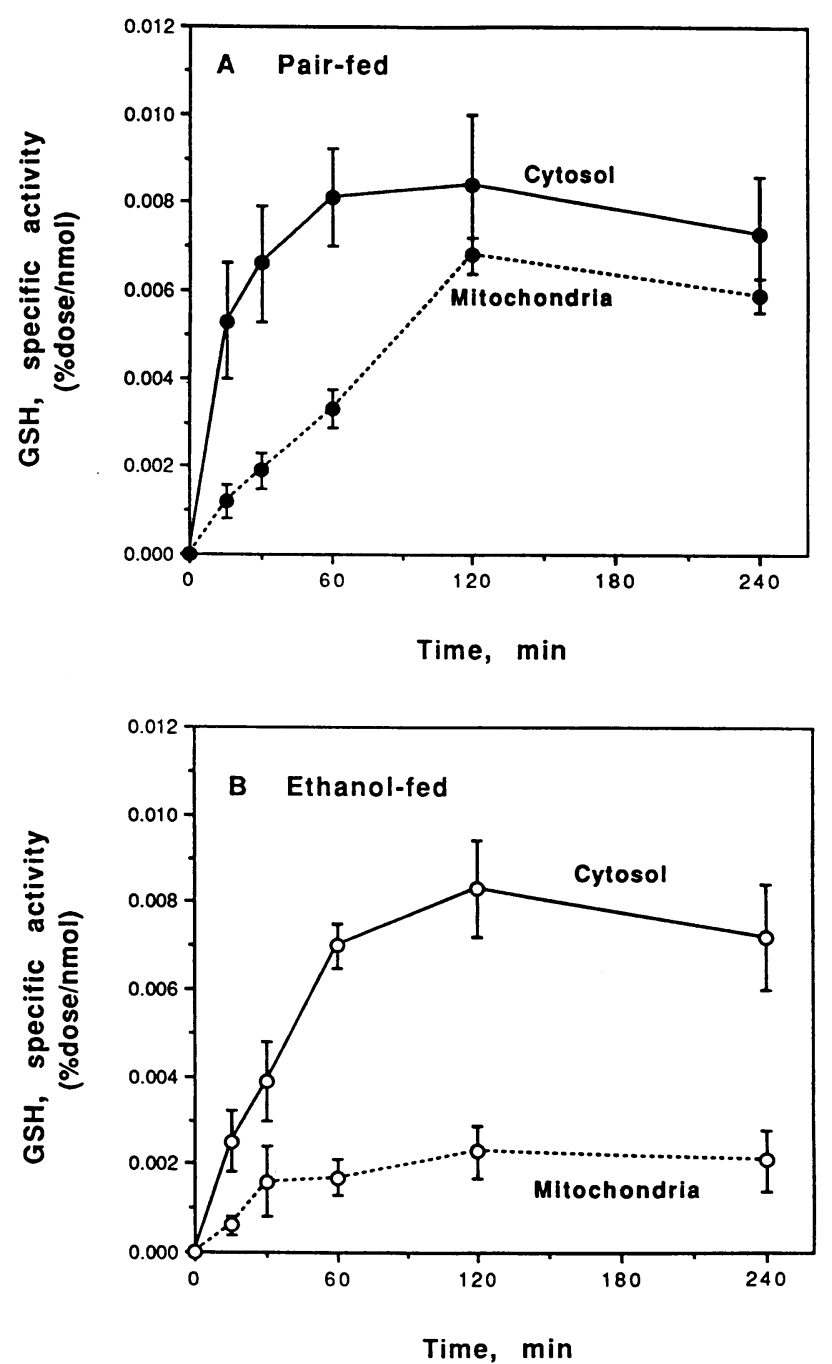

Figure 3. Time-course of GSH specific activity in pair-fed and ethanol-fed cells after depletion with DEM. Conditions were exactly as those of Fig. 2. The specific activity of GSH was calculated from HPLC by dividing the GSH counts from the ${ }^{35} \mathrm{~S}$-cpm channel expressed as percent of the dose by the GSH mass from the UV channel. $(A)$ Pair-fed cells, $(-\bullet-)$ cytosol and (--๑--) mitochondrial fractions, and $(B)$ ethanol-fed cells, (-O -$)$ cytosol and (--O--) mitochondrial fractions. Data are mean \pm SD of $n=7$ cell preparations for each group.

after correction for recovery of marker enzymes. A steady level of GSH for both pools was observed with no significant change over $2 \mathrm{~h}$. Whereas the cytosolic pool from ethanol-fed liver $(2.9 \pm 0.4 \mu \mathrm{mol} / \mathrm{g})$ contained the same level as the pair-fed livers $(2.9 \pm 0.4 \mu \mathrm{mol} / \mathrm{g})$, the mitochondrial pool showed a significantly decreased pool size $(0.45 \pm 0.057$ vs. $0.31 \pm 0.018 \mu \mathrm{mol} / \mathrm{g}$ for pair-fed and ethanol-fed livers, $P<0.05, n=4$ and 5, respectively). Under these steady-state conditions, the rate of incorporation of labeled precursor methionine and change in the total and, thus, the specific activity of GSH was indistinguishable in cytosol from control and ethanol livers (Fig. 6). However, the profiles of mitochondrial specific activity were markedly different. Pair-fed mitochondrial specific activity lagged behind the cytosol, reaching the same specific activity by $90 \mathrm{~min}$. However, in the ethanol-fed case, the rise in the mito- 

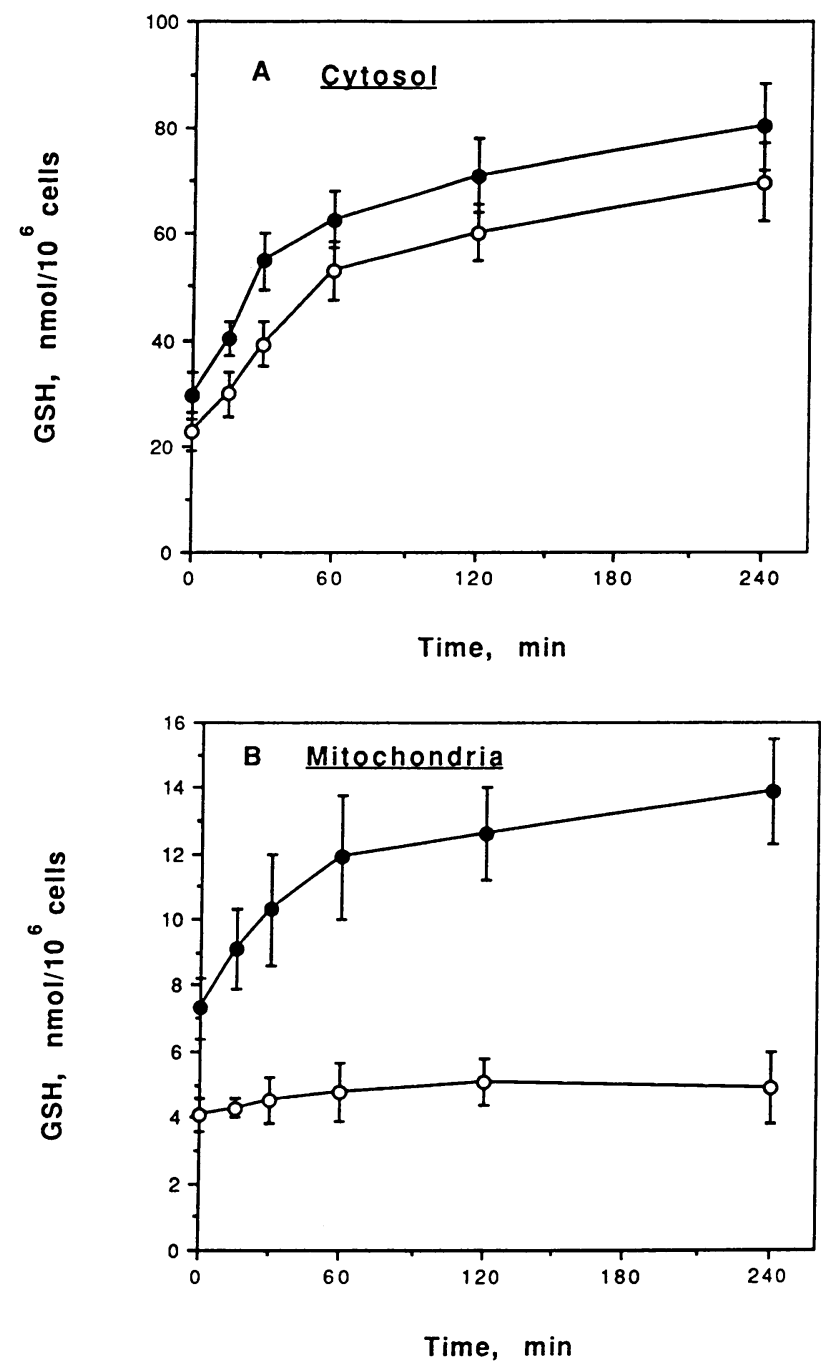

Figure 4. Synthesis of GSH in cytosol and mitochondrial fractions from repleted pair- and ethanol-fed cells. Conditions were the same as described for Fig. 2 except that cells were not preincubated with DEM to deplete GSH. $(A)$ Cytosol fraction and $(B)$ mitochondrial fraction for (- $\bullet$ ) pair-fed and (-O-) ethanol-fed-cells. Data are mean $\pm \mathrm{SD}$ of $n=3$ cell preparations for each group.

chondrial specific activity lagged far behind and did not reach the specific activity of the cytosol in the 2 -h period of our observation (Fig. 6).

The cytosol- and mitochondrial-specific GSH activity data were fitted with a two-compartment model as described in Methods. The fits are shown by the continuous lines in Fig. 6 for both groups. The numerical values of the computed fractional rates are shown in Table II. As can be seen, there was a statistically significant $(P<0.01) 36 \%$ decrease in the fractional rate of transport of cytosolic GSH to the mitochondria in the ethanol-fed group, as compared to the pair-fed. This decrease translates into an identical percent decrease in the mass transport rate, because the cytosolic GSH pool sizes are essentially identical in the two groups (Table II).

Effects of GSH-EE on mitochondrial GSH and susceptibility to lethal toxicity of $t-B O O H$. We attempted to normalize the mitochondrial GSH in the ethanol case. As is apparent in Figs. 2 and 4, raising cytosol GSH through precursor incorporation
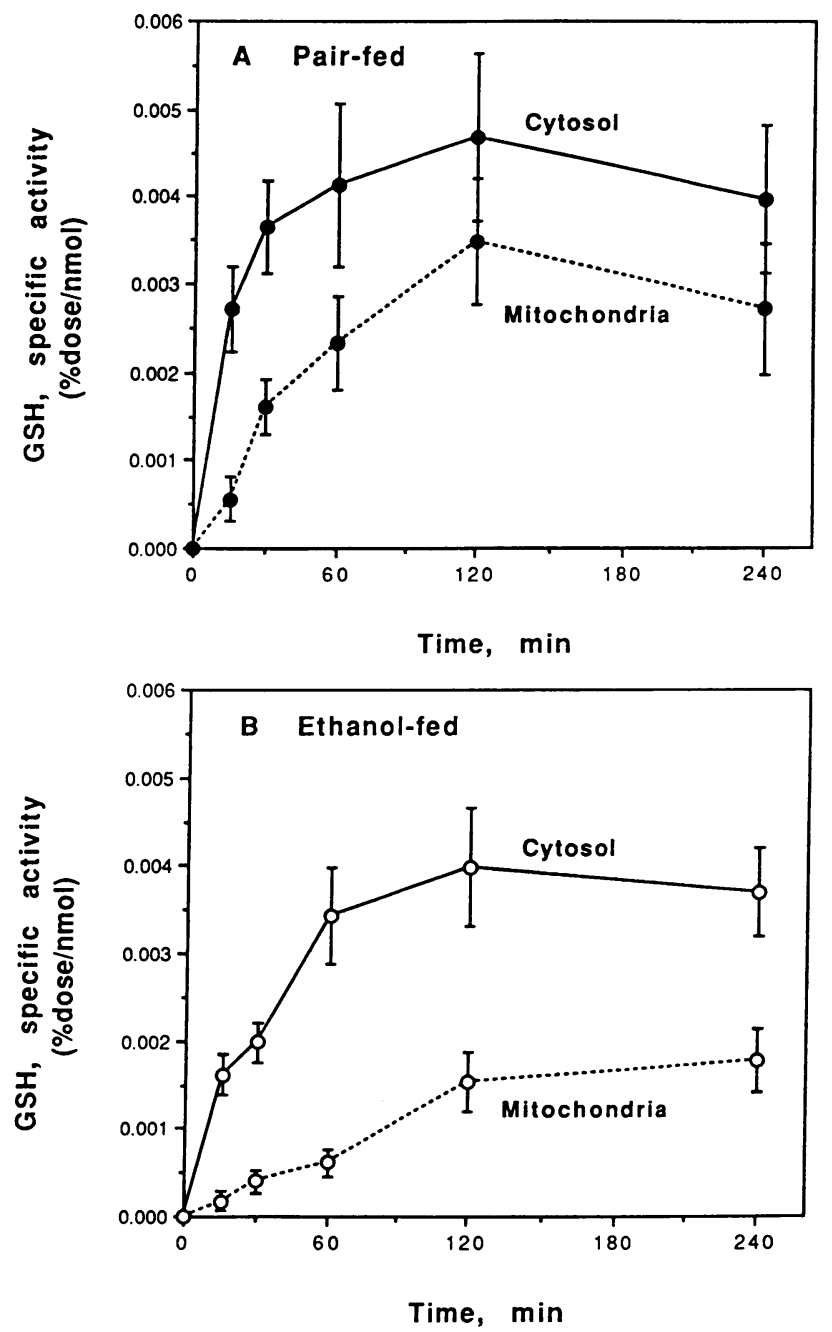

Figure 5. Time course of GSH specific activity of repleted pair- and ethanol-fed cells. The GSH specific activity was determined as

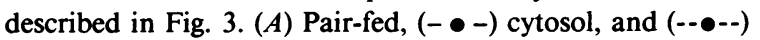
mitochondrial fractions, and $(B)$ ethanol-fed cells, $\left(-O_{-}\right)$cytosol, and $\left(---^{--)}\right.$mitochondrial fractions. Data are mean \pm SD of $n=3$ cell preparations for each group.

did not raise mitochondrial GSH. Furthermore, incubations with GSH were unsuccessful in raising cellular or mitochondrial GSH (not shown). We turned to the alternative strategy of using the GSH-EE. Hepatocytes isolated from ethanol-fed rats after 2 wk of feeding, showed the expected selective decreased mitochondrial GSH content compared to pair-fed cells (Fig. 7), as described previously (9). When cells were incubated with GSH-EE for $2 \mathrm{~h}$, both cytosol and mitochondrial GSH pool sizes increased significantly in both groups to levels that were not significantly different between pair- and ethanol-fed cells. Treatment of cells with a moderate dose of DEM depleted the cytosol pool of GSH to a much greater extent than the mitochondrial pool of GSH. Thus, cells incubated with DEM immediately after isolation or after preincubation with GSH-EE were depleted by $85-90 \%$ of the starting cytosol GSH with no significant difference between the pair-fed and ethanol-fed cells, whereas the mitochondrial GSH pool size remained at $70-85 \%$ of the initial level after DEM treatment. However, the 
Table I. Relative Enrichment and Recovery of Enzymatic Activities in Cytosol and Mitochondrial Fractions from Pairand Ethanol-fed Livers

\begin{tabular}{|c|c|c|c|c|c|c|}
\hline & \multicolumn{3}{|c|}{ Pair-fed } & \multicolumn{3}{|c|}{ Ethanol-fed } \\
\hline & Protein & SDH & LDH & Protein & SDH & LDH \\
\hline & $m g / g$ liver & & & $m g / g$ liver & & \\
\hline Cytosol & $90.7 \pm 23.0$ & $\begin{array}{c}0.4 \pm 0.3 \\
(7.5 \pm 0.9)\end{array}$ & $\begin{array}{c}2.8 \pm 0.7 \\
(91.5 \pm 7.5)\end{array}$ & $93.1 \pm 25.0$ & $\begin{array}{c}0.4 \pm 0.1 \\
(6.5 \pm 0.6)\end{array}$ & $\begin{array}{l}2.9 \pm 0.9 \\
(91 \pm 7.6)\end{array}$ \\
\hline Mitochondria & $50.0 \pm 4.7$ & $\begin{array}{l}4.4 \pm 1.1 \\
(59 \pm 6.1)\end{array}$ & $\begin{array}{c}0.5 \pm 0.3 \\
(1.4 \pm 0.3)\end{array}$ & $46.2 \pm 14.4$ & $\begin{array}{l}4.1 \pm 0.6 \\
(54 \pm 4.1)\end{array}$ & $\begin{array}{c}0.3 \pm 0.2 \\
(1.2 \pm 0.2)\end{array}$ \\
\hline
\end{tabular}

The relative enrichment of the enzymatic activities is calculated as the ratio of fraction/homogenate enzyme specific activities. The number in parentheses is the percentage of the total activity from homogenate recovered in the corresponding fraction. Results are mean $\pm \mathrm{SD}$ of $n=4$ and 5 for pair-fed and ethanol-fed livers.
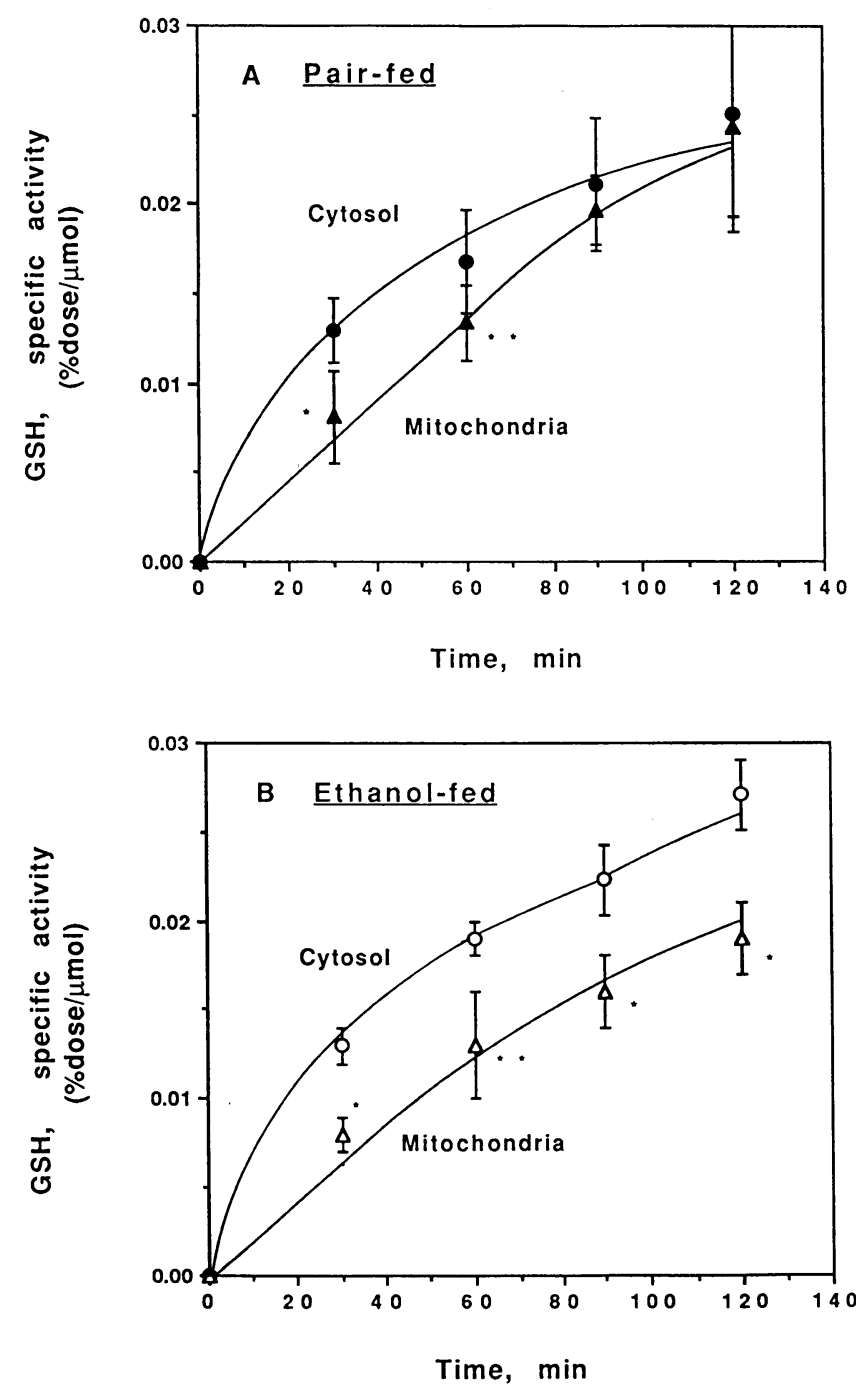

Figure 6. GSH specific activity time course from pair-fed and

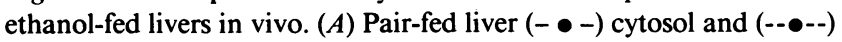
mitochondrial fractions, and $(B)$ ethanol-fed liver (- $\left.O_{-}\right)$cytosol and (--O--) mitochondrial fractions. Data are mean \pm SD of $n=4$ and 5 for pair-fed and ethanol-fed rats, respectively. ${ }^{*} P<0.01{ }^{* *} P<0.05$ mitochondria vs. the corresponding cytosol fraction using paired $t$ test. The solid lines are the fits of the two-compartment model to these data (see Methods). mitochondrial GSH content in the GSH-EE + DEM condition was significantly higher $(P<0.01)$ in either pair- or ethanol-fed cells compared to DEM treatment. Of note, the mitochondrial GSH in the ethanol case after GSH-EE + DEM was nearly identical to normal controls $( \pm \mathrm{DEM})$. Thus, by manipulating cytosol and mitochondrial GSH with GSH-EE and DEM, we produced conditions in which the mitochondrial pool was normal in the ethanol case and the cytosol pool was low and not different between the groups. These conditions were then used to assess the susceptibility to oxidant stress.

After DEM or GSH-EE + DEM treatment, cells were incubated with various doses of t-BOOH (0.1-5 mM) for $45 \mathrm{~min}$. Previous studies showed that at this time interval, the percent cell death reached a plateau and did not increase significantly thereafter (Fernández-Checa, J. C., and N. Kaplowitz, unpublished observations). Fig. 8 shows the dose-response curves for cell death with t-BOOH. In the ethanol-fed cells, there was a shift to the left of the dose-response curve compared to pair-fed cells, indicating a greater susceptibility to the lethal oxidative stress induced by t-BOOH. Both pair- and ethanol-fed cells were protected by preincubation with GSH-EE with a shift in the dose response curves to the right. Of particular note, in the

Table II. Rates of GSH Transport between the Cytosolic and Mitochondrial Pools

\begin{tabular}{|c|c|c|c|}
\hline & $\begin{array}{l}\text { Pair-fed } \\
(n=4)\end{array}$ & $\begin{array}{c}\text { Ethanol-fed } \\
\quad(n=5)\end{array}$ & $\begin{array}{c}\% \\
\text { decrease }\end{array}$ \\
\hline \multicolumn{4}{|l|}{ Fractional rates $(\% / \mathrm{min})$} \\
\hline Cytosol to mitochondria & $0.614 \pm 0.098$ & $0.394 \pm 0.075^{*}$ & 36 \\
\hline Mitochondria to cytosol & $3.94 \pm 0.63$ & $3.64 \pm 0.69$ & 7.6 \\
\hline \multicolumn{4}{|l|}{ Pool sizes $(\mathrm{nmol} / \mathrm{g})$} \\
\hline Cytosolic GSH & $2938 \pm 419$ & $2921 \pm 431$ & 0.6 \\
\hline Mitochondrial GSH & $457 \pm 57$ & $316 \pm 18^{*}$ & 31 \\
\hline \multicolumn{4}{|l|}{ Mass fluxes ( $\mathrm{nmol} / \mathrm{min}$ per $\mathrm{g}$ ) } \\
\hline Cytosol to mitochondria & $18.0 \pm 3.8$ & $11.5 \pm 2.9^{\ddagger}$ & 36 \\
\hline Mitochondria to cytosol & $18.0 \pm 3.8$ & $11.5 \pm 2.9^{\ddagger}$ & 36 \\
\hline
\end{tabular}

Results were determined by compartmental analysis and modeling using the tracer kinetic data shown in Fig. 6 (fits shown by the continuous lines in Fig. 6; see text for details). ${ }^{*} P<0.01$ compared to pair-fed. ${ }^{\ddagger} P<0.025$ compared to pair-fed. 

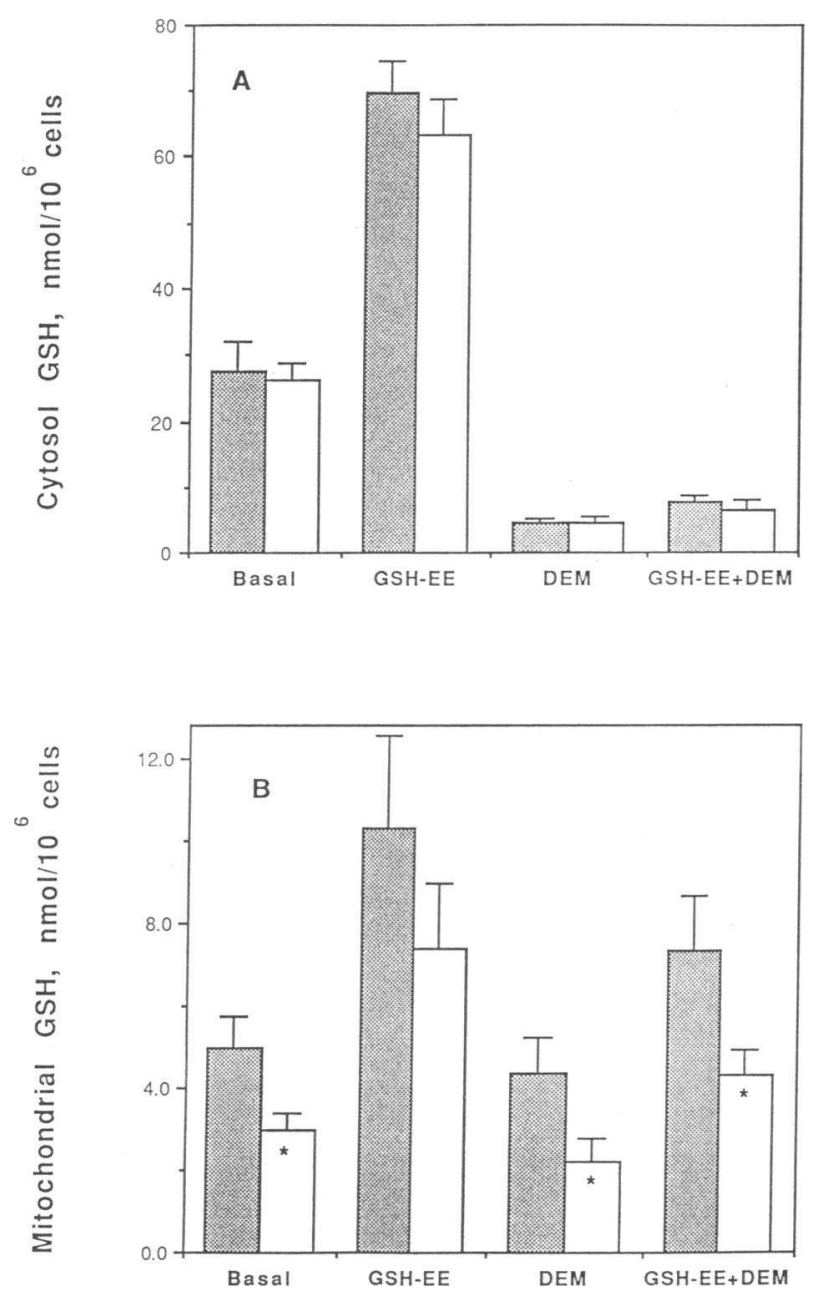

Figure 7. Cytosolic $(A)$ and mitochondrial $(B)$ GSH pool sizes from pair-fed (hatched bars) and ethanol-fed cells (open bars) isolated after 2 wk of dietary treatment. Cells were treated with GSH-EE ( $7 \mathrm{mM}$ for $2 \mathrm{~h})$. Starting cells or cells after preincubation with the GSH ester (GSH-EE, $7 \mathrm{mM}$ for $2 \mathrm{~h}$ ) were then treated with diethylmaleate (DEM) for $10 \mathrm{~min}$ at 0.2 or $0.32 \mathrm{mM} \mathrm{DEM}$, respectively. After this DEM preincubation, cells were separated into cytosol and mitochondrial fractions by digitonin (see Methods) and GSH determined in both pools. Data is mean $\pm \mathrm{SD}$ of $n=4$ cell preparations for each. ${ }^{*} P<0.01$ versus pair-fed cells using unpaired $t$ test.

ethanol-fed cells, the dose-response after incubation with the GSH-EE was almost identical to the dose-response curve from the pair-fed cells without the ester. This difference in susceptibility to peroxidative-induced cell death and protection by incubation with GSH-EE was related to differences in the mitochondrial GSH pool size as shown in Fig. $8 B$ for the 0.5 and 1 $\mathrm{mM}$ doses of $\mathrm{t}-\mathrm{BOOH}$. Raising mitochondrial GSH (and not cytosol) in the ethanol cells to the levels found in pair-fed cells with the use of GSH-EE, lowered cell death in the ethanol cells to match the pair-fed cells.

\section{Discussion}

We have previously observed an impaired capacity to sequester GSH in the particulate fraction of hepatocytes from ethanolfed rats (9). Our previous work and that of others (14), which have employed the digitonin permeabilization technique, have
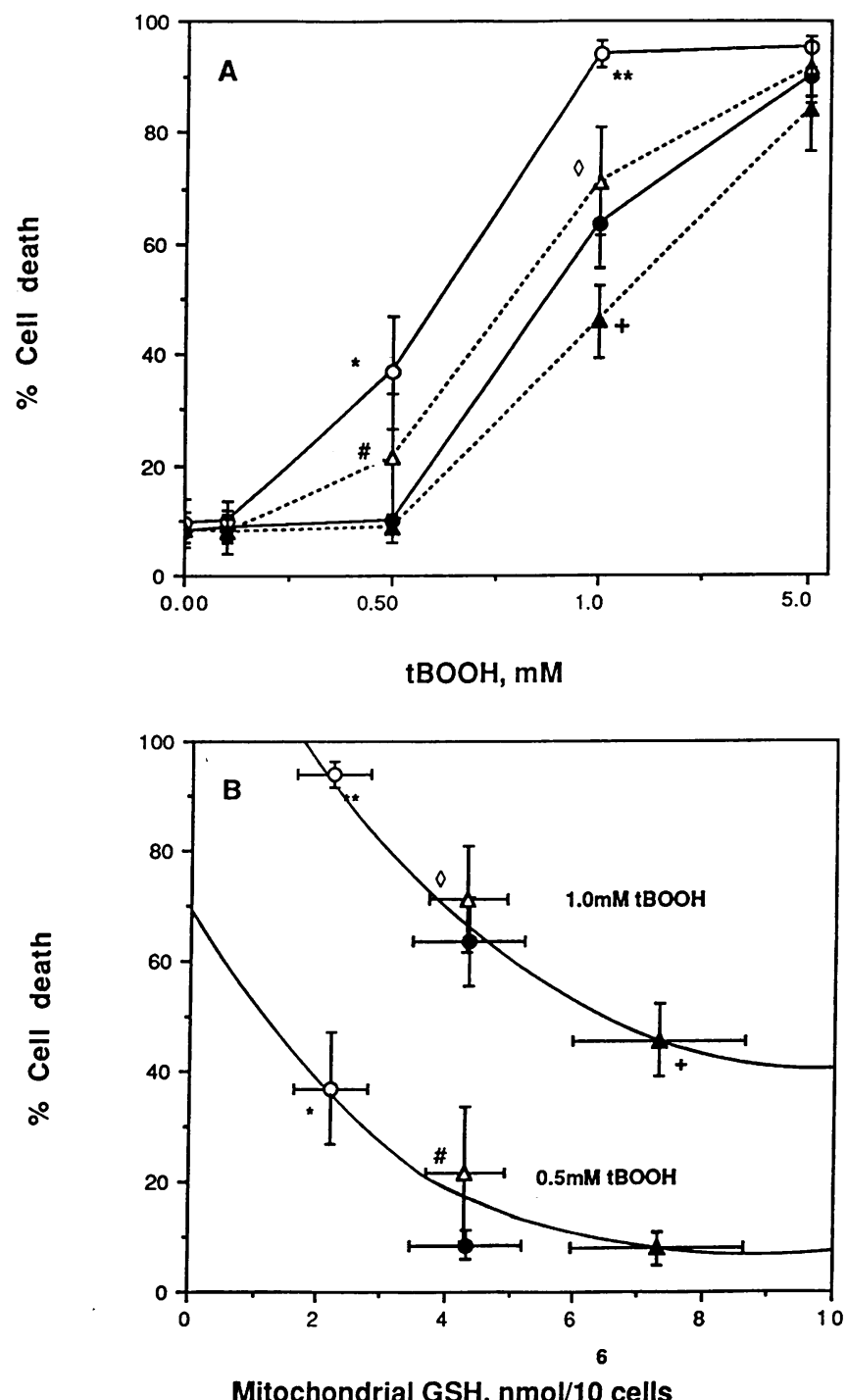

Figure 8 . Susceptibility to t-BOOH-induced cell death. $(A)$ Shows the dose-response curves obtained by incubating pair- $(\bullet, \Lambda)$ and ethanolfed cells $(0, \Delta)$ with various doses of $\mathrm{t}-\mathrm{BOOH}$ for $45 \mathrm{~min}$ in sulfur amino acid-free culture medium after DEM pretreatment as described in Fig. 7. Solid lines represent data without the GSH-EE preincubation, and broken lines with ester preincubation. $(B)$ The relationship of the initial mitochondrial GSH pool size and cell death at two doses of $\mathrm{t}-\mathrm{BOOH}$. The initial mitochondrial GSH content was established by incubation of basal cells $(O, \bullet)$ or cells that were first preincubated with the ester $(\Delta, \Delta)$ with DEM, 0.2 or $0.32 \mathrm{mM}$ for 10 min, respectively. Open symbols represent ethanol-fed cells, and closed symbols represent pair-fed cells. Data represent mean \pm SD of $n=4$ cell preparations for each point. ${ }^{*} P<0.01$ and ${ }^{* *} P<0.001$ vs. pair-fed controls comparison by the unpaired $t$ test; ${ }^{\prime \prime} P<0.01$ and ${ }^{\diamond} P$ $<0.05$ vs. ethanol without the ester preincubation and ${ }^{+} P<0.02$ vs. pair-fed control before the ester incubation, compared by the paired $t$ test.

been based on the assumption that the compartmentalized GSH in the particulate fraction resides in mitochondria. Therefore, we first performed density gradient fractionation of this pellet from digitonin-permeabilized normal cells. The results support the validity of the assumption that nearly all the sequestered GSH is in mitochondria and not in other organelles. 
We have confirmed that in isolated hepatocytes, chronic ethanol feeding leads to an impaired net accumulation of mitochondrial GSH (9). However, we considered two possible mechanisms for such a defect: impaired uptake of GSH by mitochondria (decreased entry) or impaired capacity to retain GSH in mitochondria (increased release). The latter seemed a plausible alternative because ethanol leads to mitochondrial damage which might cause GSH to leak out or in some other way impair retention of GSH by mitochondria. To distinguish between these possibilities we examined the transfer rate of labeled GSH synthesized from precursor methionine in cytosol into the mitochondria. To optimize rapid incorporation of label into cytosol GSH, we first depleted the cells of GSH and allowed the cells to synthesize GSH de novo rapidly and perhaps maximally and also performed experiments in repleted cells. The accumulation of labeled GSH into mitochondria lagged behind cytosol in the controls as expected (7) but reached a plateau, or isotopic equilibrium between cytosol and mitochondria by $2 \mathrm{~h}$. If the defect in mitochondria in the ethanol-fed case is due to inability to retain GSH, an isotopic equilibrium with cytosol would be expected to be arrived at very early (due to a rapid exchange between the two pools). However, the rate of entry of labeled GSH into mitochondria and the reaching of isotopic equilibrium was markedly delayed. This outcome supports the view that the major defect in mitochondria of hepatocytes from ethanol-fed rats leading to a diminished GSH pool size is an impaired capacity to take up cytosolic GSH and not an increased GSH release from or leakiness of the mitochondria.

All our previous work has been conducted in isolated hepatocytes $(8,9)$. To exclude the possibility that our results could somehow be artifactually influenced by the performance of mitochondria in hepatocytes in suspension during prolonged incubations under unphysiologic conditions, we attempted to verify our results by examining the exchange of GSH labeled with precursor in cytosol and mitochondria in vivo. Such a concern regarding potential in vitro artifactual effects was of particular importance to us because the increase in mitochondrial GSH specific activity virtually ceased after $2 \mathrm{~h}$ incubation in the ethanol cells, suggesting abrupt cessation of function.

In different lots of rats treated with the Lieber-DeCarli diets, we have observed some minor variability in GSH pool sizes. In the present studies, we observed no difference in cytosol GSH, in agreement with others $(10,32,33)$ but still observed a significant $31 \%$ decrease in mitochondrial GSH pool in the ethanol case. It should be noted that this is the smallest change we have reported heretofore. Our tracer-kinetic experiments in vivo confirmed the in vitro findings in showing close correspondence in labeling of GSH in cytosol of the pair-fed and ethanol-fed livers but a major difference in appearance of labeled GSH in mitochondria. However, in contrast to the cessation of increase in mitochondrial GSH specific activity in vitro, in the in vivo ethanol case a gradual rise was observed. The explanation for the apparently more severe defect in vitro is unknown but is likely to be due to the conditions of isolation and incubations and the ethanol cells being more susceptible to adverse effects of these conditions. In the pair-fed case, the mitochondrial GSH reached isotopic equilibrium with cytosol by $90 \mathrm{~min}$ in vivo, but a marked delay in appearance of labeled GSH in ethanol-fed rat liver mitochondria was observed, consistent with impaired uptake of cytosolic GSH by mitochondria. Indeed, our compartmental analysis and modeling, by fitting the data from the tracer-kinetic experiments in vivo, quantitatively established a $36 \%$ suppression in the fractional and mass rates of cytosolic-mitochondrial transport (exchange) of GSH in the ethanol-fed as compared to pair-fed groups. Interestingly, the percent decline in this transport rate is very similar to the decline in the pool size of mitochondrial GSH $(31 \%)$. Our modeling of the in vivo tracer kinetic data has also provided for the first time quantitative estimates of mitochondrial GSH transport. In controls, the mitochondrial GSH transport rate of $18 \mathrm{nmol} / \mathrm{min}$ per $\mathrm{g}$ liver is comparable to the sinusoidal efflux rate of GSH in repleted liver (4). In fact, at the cytosol GSH levels found in the present studies in pair-fed controls $(2.9 \mu \mathrm{mol} / \mathrm{g})$, the predicted sinusoidal efflux rate is $\sim 14$ $\mathrm{nmol} / \mathrm{min}$ per $\mathrm{g}(4)$. The rate of uptake or mass transport of GSH into mitochondria under the steady-state conditions requires an equal mass transport rate out of mitochondria. Thus, based on our current finding, mitochondrial GSH turns over with a half-life of $\sim 18 \mathrm{~min}$. We have defined the exchange of GSH between cytosol and mitochondria for the first time and demonstrated that the transport into mitochondria is quantitatively a major component of cytosol GSH turnover and that in contrast to previous beliefs (14) mitochondria GSH turnover is very rapid. In addition, we have further clarified the mechanism for a diminished mitochondrial pool in ethanol-fed rats by demonstrating that mitochondrial GSH uptake but not efflux is impaired. More work on the nature of the defect in uptake induced by ethanol is needed.

A diminished mitochondrial pool of GSH may play a role in the pathogenesis of alcoholic liver injury by increasing the susceptibility to oxidant stress. There is considerable evidence to suggest that the mitochondrial GSH pool is critical for cell viability through the regulation of mitochondrial inner membrane permeability by maintaining sulfhydryls groups in the reduced state (34), although there may be some exceptions to this rule (35). To assess the importance of such a hypothesis, a strategy for correcting the defect and normalizing the mitochondrial GSH pool is critical. We were disappointed to find in our previous and present work that marked increases in cytosol GSH by de novo synthesis from methionine did not lead to a normalization of the mitochondrial GSH in the hepatocytes of ethanol-fed rats (9). Therefore, we turned to an alternative strategy, namely the use of GSH-EE, because Meister and coworkers $(15,25,27)$ have indicated that GSH-EE normalized mitochondrial GSH in skeletal muscle, heart and lung $(15,27)$ and liver cells (27) and that mitochondria contain the esterase activity necessary to release GSH from GSH-EE $(15,25-27)$. We have examined the pathophysiologic consequences of a selective decreased mitochondrial GSH pool size in the ethanol-fed cells by setting up conditions in which pair- and ethanol-fed cells had the same starting and low levels of cytosolic GSH, while still differing in the mitochondrial GSH pool size to minimize any effect of cytosolic GSH and to avoid possible confounding effects on susceptibility to oxidant stress by differences in starting cytosol GSH. Furthermore, additional synthesis of GSH was avoided by incubating the cells in sulfur-amino acid-free medium. The GSH-EE raised the mitochondrial GSH in ethanol-fed cells to levels identical to normal hepatocytes. This increase in mitochondrial GSH clearly could not be explained by an increase in cytosol GSH in the ethanol case because our present and previous findings using methionine to raise cytosol GSH to the same extent as the ester did not lead to a normalization of the mitochondrial GSH (9). We observed a 
greater susceptibility to t-BOOH-induced lethal oxidant stress in the ethanol-fed cells, and a protection by increasing the mitochondrial GSH pool size to levels similar to the pair-fed cells with preincubation with GSH-EE. This strongly suggests that the increased susceptibility to oxidant stress in hepatocytes from ethanol-fed rats is due to the decreased mitochondrial GSH. Thus, raising the mitochondrial GSH in the ethanol case to near normal reversed the increased susceptibility to lethal oxidant stress making these cells behave like normal cells, providing strong support for the potential pathophysiologic importance of the ethanol-induced impairment of mitochondrial GSH uptake and consequent diminished pool size. Furthermore, correcting the depleted mitochondrial GSH pool with the use of GSH-EE may provide a strategy for therapeutic intervention in protecting the liver of chronic alcoholics against physiologic or ethanol-induced oxidant stress. In addition, it is recognized that chronic ethanol exposure increases the susceptibility to acetaminophen toxicity $(10,36,37)$. Although induction of cytochrome P450IIE1 may be important in enhancing toxicity of acetaminophen, the depletion of mitochondrial GSH may also contribute. Nelson and associates (38) have shown that mitochondria are a critical target of covalent binding of the reactive metabolite of acetaminophen. Thus, depletion of mitochondrial GSH may play an important role in increasing the susceptibility of hepatocytes of alcoholic subjects to toxicity from endogenous or exogenous oxidants and electrophilic metabolites of drugs.

\section{Acknowledgments}

The technical assistance of John Kuhlenkamp is greatly appreciated.

This work was supported by Veterans Administration Medical Research Funds and National Institutes of Health grant DK30312.

\section{References}

1. Larsson, A., S. Orrenius, A. Holmgren, and B. Mannervik. 1983. Functions of Glutathione: Biochemical, Physiological, Toxicological and Clinical Aspects. Raven Press, New York. 393 pp.

2. Meister, A., and M. E. Anderson. 1983. Glutathione. Annu. Rev. Biochem. 52:711-760.

3. Kaplowitz, N., T. Y. Aw, and M. Ookhtens. 1985. The regulation of hepatic glutathione. Annu. Rev. Pharmacol. Toxicol. 25:715-744.

4. Ookhtens, M., K. Hobdy, M. C. Corvasce, T. Y. Aw, and N. Kaplowitz. 1985. Sinusoidal efflux of glutathione in the perfused rat liver: evidence for a carrier-mediated process. J. Clin. Invest. 75:258-265.

5. Kaplowitz, N., D. Eberle, J. Petrini, J. Touloukian, M. C. Corvasce, and J. Kuhlenkamp. 1983. Factors influencing the efflux of glutathione into bile in rats. J. Pharmacol. Exp. Ther. 224:141-147.

6. Wahllander, A., A. Soboll, and H. Sies. 1975. Hepatic mitochondrial and cytosolic glutathione content and the subcellular distribution of GSH-S-transferases. FEBS (Fed. Eur. Biochem. Soc.) Lett. 97:138-140.

7. Griffith, O. W., and A. Meister. 1985. Origin and turnover of mitochondrial glutathione. Proc. Natl. Acad. Sci. USA. 82:4668-4672.

8. Fernández-Checa, J. C., M. Ookhtens, and N. Kaplowitz. 1987. Effect of chronic ethanol feeding on rat hepatocytic glutathione: compartmentation, efflux and response to incubation with ethanol. J. Clin. Invest. 80:57-62.

9. Fernández-Checa, J. C., M. Ookhtens, and N. Kaplowitz. 1989. Effects of chronic ethanol feeding on rat hepatocytic glutathione: relationship of cytosolic glutathione to efflux and mitochondrial sequestration. J. Clin. Invest. 83:12471252.

10. Kaplowitz, N., J. C. Fernández-Checa, and M. Ookhtens. 1989. Glutathione, alcohol and hepatotoxicity. In Nutrition and the Origins of Disease. C. H. Halsted and R. B. Rucker, editors. Academic Press, Inc., San Diego, CA. $267-$ 281.

11. Rottenberg, H., D. E. Robertson, and E. Rubin. 1980. The effect of eth- anol on the temperature depence of respiration and ATPase activities of rat liver mitochondria. Lab. Invest. 42:318-326.

12. Thayer, W. S., and E. Rubin. 1979. Effect of chronic ethanol intoxication on oxidative phosphorylation in rat liver submitochondrial particles. J. Biol. Chem. 254:7717-7723.

13. Meredith, M. J., and D. J. Reed. 1983. Depletion in vitro of mitochondrial glutathione in rat hepatocytes and enhancement of lipid peroxidation by adriamycin and 1,3-bis(2-chloroethyl)-1-nitrosourea (BCNU). Biochem. Pharmacol. 32:1383-1388.

14. Meredith, M. J., and D. J. Reed. 1982. Status of the mitochondrial pool of glutathione in the isolated hepatocytes. J. Biol. Chem. 257:3747-3753.

15. Martensson, J., and A. Meister. 1989. Mitochondrial damage in muscle occurs after marked depletion of glutathione and is prevented by giving glutathione monoester. Proc. Natl. Acad. Sci. USA. 86:471-475.

16. DeCarli, L. M., and C. S. Lieber. 1967. Fatty liver in the rat after prolonged intake of ethanol with a nutritionally adequate new liquid diet. J. Nutri. 91:131-138.

17. Moldeus, P., P. Hogberg, and S. Orrenius. 1978. Isolation and use of liver cells. Methods Enzymol. 51:60-70.

18. Aw, T. Y., M. Ookhtens, and N. Kaplowitz. 1984. Inhibition of glutathione efflux from isolated rat hepatocytes by methionine. J. Biol. Chem. 259:93559358.

19. Fernández-Checa, J. C., C. Ren, T. Y. Aw, M. Ookhtens, and N. Kaplowitz. 1988. Effect of membrane potential and cellular ATP on glutathione efflux from isolated rat hepatocytes. Am. J. Physiol. 255:G403-G408.

20. Fernández-Checa, J. C., T. Maddatu, M. Ookhtens, and N. Kaplowitz. 1990. Effect of GSH synthesis on the inhibition of GSH efflux by methionine: studies in isolated hepatocytes and perfused rat liver. Am. J. Physiol. 258:G963G975.

21. Fariss, M. W., and D. J. Reed. 1987. High performance liquid chromatography of thiols and disulfides: dinitrophenol derivatives. Methods Enzymol. 143:101-109.

22. Solheim, A. E., and P. O. Seglen. 1980. Subcellular distributions of proteolitically generated valine in isolated rat hepatocytes. Eur. J. Biochem. 107:587596.

23. Reinhart, P. H., W. M. Taylor, and F. L. Bygrave. 1982. A procedure for the rapid preparation of mitochondria from rat liver. Biochem. J. 204:731-735.

24. Anderson, M. E., and A. Meister. 1989. Glutathione monoesters. Anal. Biochem. 183:16-20.

25. Puri, R. N., and A. Meister. 1983. Transport of glutathione, as $\gamma$-glutamylcysteinilglycyl ester, into liver and kidney. Proc. Natl. Acad. Sci. USA. 80:25582560 .

26. Wellner, V. P., M. E. Anderson, R. N. Puri, G. L. Jensen, and A. Meister. 1984. Radioprotection by glutathione ester: transport of glutathione ester into human lymphoid cells and fibroblasts. Proc. Natl. Acad. Sci. USA. 81:4732-4735.

27. Martensson, J., A. Jain, W. Frayer, and A. Meister. 1989. Glutathione metabolism in the lung: inhibition of its synthesis leads to lamellar body and mitochondrial defects. Proc. Natl. Acad. Sci. USA. 86:5296-5300.

28. Tietze, F. 1969. Enzymatic method for quantitative determination of nanogram amounts of total and oxidized glutathione: applications to mammalian blood and other tissues. Anal. Biochem. 77:502-522.

29. Hatefi, Y., and D. L. Stiggall. 1978. Preparation and properties of succinate: ubiquinone oxidoreductase (complex II). Methods Enzymol. 53:21-27.

30. Fiske, C. H., and Y. SubbaRow. 1925. Quantitation of inorganic phosphorus. J. Biol. Chem. 66:375-378.

31. Andersson, B. S., and D. P. Jones. 1985. Use of digitonin fractionation to determine mitochondrial transmembrane ion distribution in cells during anoxia. Anal. Biochem. 146:164-172.

32. Vendemiale, G., E. Jayatilleke, S. Shaw, and C. S. Lieber. 1984. Depression of biliary glutathione excretion by chronic ethanol feeding in the rat. Life Sci. 34:1065-1073.

33. Pierson, J. L., and M. C. Mitchell. 1986. Increased hepatic efflux of glutathione after chronic ethanol feeding. Biochem. Pharmacol. 35:1533-1537.

34. Reed, D. J. 1990. Glutathione: toxicological implications. Annu. Rev. Pharmacol. Toxicol. 30:603-631.

35. Ku, R. H., and R. E. Billings. 1986. The role of mitochondrial glutathione and cellular protein sulfhydryls in formaldehyde toxicity in glutathione-depleted rathepatocytes. Arch. Biochem. Biophys. 247:183-189.

36. Moldeus, P. B. Andersson, A. Norling and K. Ormstad. 1980. Effect of chronic administration on drug metabolism in isolated hepatocytes with emphasis on paracetamol activation. Biochem. Pharmacol. 29:1741-1745.

37. Black, M., and J. Raucy, 1986. Acetaminophen, alcohol and cytochrome P-450. Ann. Intern. Med. 104:487-492.

38. Tirmenstein, M. A., and S. D. Nelson. 1989. Subcellular binding and effects on calcium homeostasis produced by acetaminophen and a nonhepatotoxic regioisomer, 3'-dydroxyacetanilide in mouse liver. J. Biol. Chem. 264:98149819. 